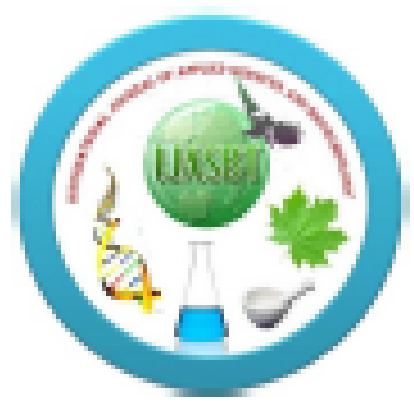

Avallable online at wwwijast.torg

International Journal of Applied Sciences and Biotechnology A Rapid Publishing Journal

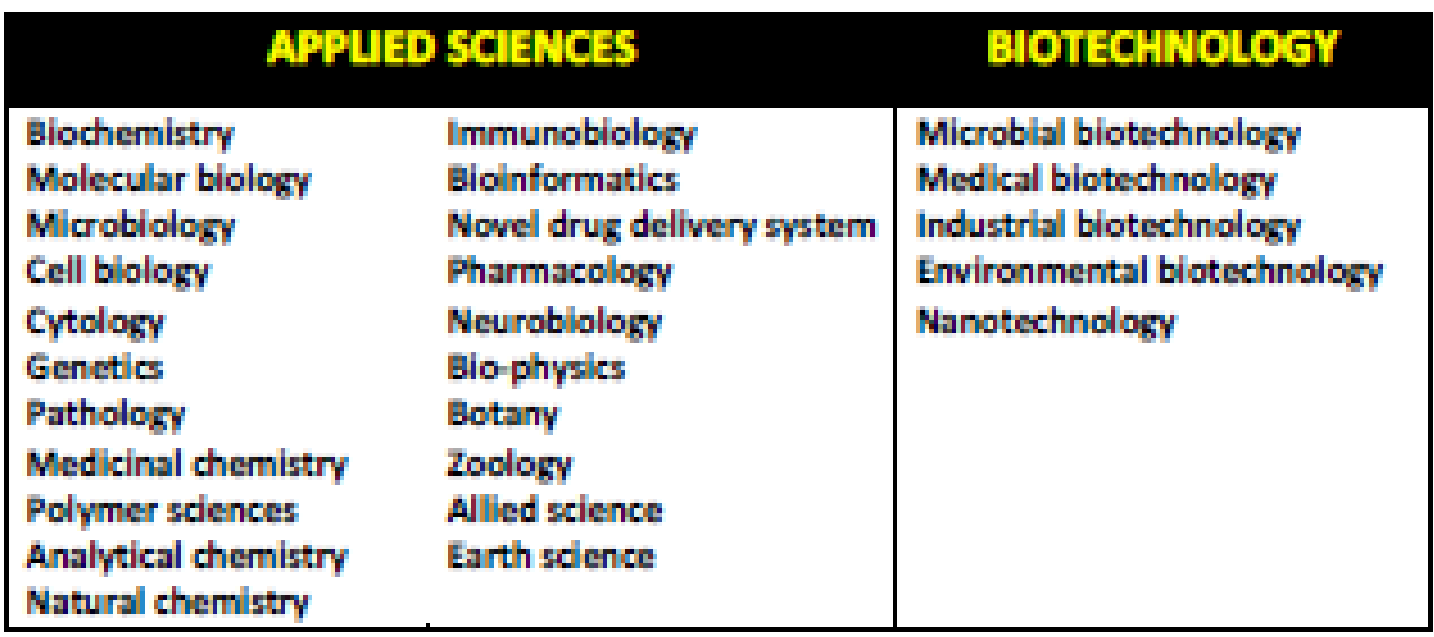

If any queries or feedback, then don't hesitate to mail us at: editor.jjasbti旦mail.com 


\title{
PHYSICO-CHEMICAL ANALYSIS OF FRESH AND PROBIOTICATED FRUIT JUICES WITH LACTOBACILLUS CASEI
}

\author{
Bathal Vijaya Kumar ${ }^{1}$, Mannepula Sreedharamurthy ${ }^{2}$, Obulam Vijaya Sarathi Reddy ${ }^{2 *}$ \\ ${ }^{1}$ Department of Biotechnology, S.V.University, Tirupati - 517502, India \\ ${ }^{2}$ Department of Biochemistry, S.V.University, Tirupati - 517502, India \\ *Corresponding Author e-mail: ovsreddy@yahoo.com
}

\begin{abstract}
The objective of this study was to find out the suitability of different fruit juices for probiotication by using Lactobacillus casei. Phyto-chemical analysis of different fruit juices (mango, sapota, grape and cantaloupe) were carried out using the standard methods. The carbohydrates, flavoniods, tannins and glycosides were present where as the alkaloids and saponins were absent in all the above fruit juices. Qualitative and quantitative analysis by TLC and DPPH methods revealed the presence of antioxidants in all the fruit juices except cantaloupe. Probiotication of fruit juices with known Lactobacillus casei decreased the $\mathrm{pH}$ and increased the titratable acidity within $72 \mathrm{~h}$. Physico-chemical properties were also determined at different time intervals (24, 48 and $72 \mathrm{~h}$ ) of probiotication. Based on the above results, it was inferred that the beverage prepared from the probiotication of fruit juices with Lactobacillus casei could be useful in providing health benefits to the consumers.
\end{abstract}

Key words: Fruit juices, phyto-chemical analysis, antioxidants, probiotication.

\section{Introduction}

Tropical fruits have their origin in the tropics and require rather a tropical or subtropical climate; and do not tolerate frost. There are hundreds of edible tropical fruits some of which have very high export potential all over the world. India is the largest producer of fruits in the world with an annual production of 46 million tons. Most of the tropical fruits are important source of antioxidants, vitamins, dietary fibres and minerals; and form a very healthy part of our diet (Reddy et al., 2012). Fruit juice could serve as a good medium for cultivating probiotics (Mattila-Sandholm et al., 2002). Furthermore, fruits and vegetables do not contain any allergens, as in case of dairy products, that might cause allergy in certain segments of the population (Luckow \& Delahunty, 2004).

Probiotics are defined as "living microorganisms, which upon ingestion in certain numbers exert health effects beyond inherent basic nutrition" (Guarner \& Schaafsma, 1998). Lactic acid bacteria (LAB), predominantly selected from the genera Lactobacillus and Bifidobacterium, constitute a significant proportion of probiotic cultures in nutritional supplements, pharmaceuticals and functional foods (Piano et al., 2006). The LABs have been added to a variety of dairy-based products such as fermented milks and yogurts for their probiotic human health benefits
(Siuta-Cruce \& Goulet, 2001). As mentioned earlier, current industrial probiotic foods are basically dairy products, which may represent inconveniences due to their lactose and cholesterol content (Heenan et al., 2004).

Technological advances have made possible to alter some structural characteristics of fruit and vegetable matrices by modifying food components in a controlled way (Betoret et al., 2003). This could make them ideal substrates for the culture of probiotics, since they already contain beneficial nutrients such as minerals, vitamins, dietary fibers and antioxidants (Yoon et al., 2004). There is a genuine interest in the development of fruit juice based functional beverages with probiotics, because they have taste profiles that are appealing to all age groups and also they are perceived as healthy and refreshing foods (Tuorila \& Cardello, 2002; Yoon et al., 2004; Sheehan et al., 2007). In recent years, consumer demand for non dairy-based probiotic products has increased. Fruit juices may be an alternative vehicle for the incorporation of probiotics, because they are rich in nutrients and do not contain starter cultures that compete for nutrients with probiotics. Furthermore, fruit juices are often supplemented with oxygen scavenging ingredients such as ascorbic acid, thus promoting anaerobic conditions. Fruit juices contain high amounts of sugars which 
could encourage probiotic growth and the decrease in the sugar content could easily be monitored using a refractometer.

Probiotication of fruit juices is beneficial, as these are rich sources of healthy nutrients such as antioxidants, vitamins, food fibers and minerals. Mango contains a high concentration of sugars, acids with good organoleptic properties, besides antioxidants and is a rich source of vitamin A (beta-carotene). Chemical composition of sapota juice revealed that it is one of the rich sources of vitamins, sugars, proteins, ascorbic acid, phenolics, carotenoids and minerals like iron, copper, zinc, calcium and potassium. Grapes are a storehouse of numerous health promoting phytonutrients such as poly-phenolic antioxidants, vitamins and minerals. Generally both fresh fruits and their juices are included in our regular diet as they give health benefits to all age groups. Juices from these sources are deemed to be advantageous because of their low allergenicity, perceived health benefits and appeal to a wide segment of the population (Sheehan et al., 2007). It is envisaged to probioticate the fruit juices for certain greater benefits. The present study is focused on phyto-chemical analysis of locally available fruit juices like mango (Mangifera indica L.), sapota (Manilkara zapota L), grape (Vitis vinifera L.) (white and black varieties) and cantaloupe (Cucumis melo). We also studied the suitability of above fruit juices for probiotication by using a proven probiotic strain of Lactobacillus casei.

\section{Material and methods}

\section{Microorganism}

Lactobacillus casei 1423 was obtained from MTCC (Microbial Type Culture Collection), Institute of Microbial Technology (IMTech), Chandigarh, India. It was grown at $37^{\circ} \mathrm{C}$ for $24 \mathrm{~h}$ in MRS (Man Rogosa Sharpe) broth and used as inoculum.

\section{Processing of different fruits}

Mango, sapota, grape (white and black) and cantalope fruits were purchased from fruit market of Tirupati, India. After collection, the fruits were allowed to ripen for a period of 5-7 days. After that, the fruits were washed with tap water followed by sterile water. Then fruits were peeled with the help of sharp knife and cut into small pieces and then pulped with the help of laboratory blender and added with $0.1 \mathrm{~g} / \mathrm{L}$ of potassium meta bisulphite as a preservative and kept in a refrigerator at $-4^{\circ} \mathrm{C}$ until further use.

\section{Extraction of fruit juices by enzyme treatment}

The fruit pulp samples obtained from various fruits were treated with $0.1 \%(\mathrm{w} / \mathrm{v})$ of commercial pectinase enzyme and incubated at $40^{\circ} \mathrm{C}$ for $2 \mathrm{~h}$. The activity of enzyme reaction was stopped by heating at $80^{\circ} \mathrm{C}$ for 5 min. The juice was extracted by passing through a cheese cloth (Kumar et al., 2009). The juice samples obtained in this manner were then subjected to analysis of phyto-chemicals, reducing sugars, total acidity, $\mathrm{pH}$ and soluble solid contents and stored at $4^{\circ} \mathrm{C}$ prior to probiotication using L. casei.

\section{Phyto-chemical analysis}

The analysis were carried out by using the standard methods (Harborne, 1992).

Test for carbohydrates: Carried out using the Fehling's and Benedict's test. The fruit juices filtrates were hydrolyzed with dil. $\mathrm{HCl}$ neutralized with alkali and heated with Fehling's A \& B solutions. Formation of red precipitate indicates the presence of reducing sugar. Fruit juice filtrates were also treated with Benedict's reagent and heated gently. Orange red precipitate indicates the presence of reducing sugars.

Detection of flavonoids: Carried out using alkaline reagent test. Fruit juices were treated with few drops of $\mathrm{NaOH}$ solution. Formation of intense yellow colour, which becomes colorless on addition of dilute acid, indicates the presence of flavonoids.

Detection of tannins: Carried out using gelatin test. To the fruit juice, $1 \%$ gelatin solution containing $\mathrm{NaCl}$ was added. Formation of white precipitate indicates the presence of tannins.

Detection of glycosides: Carried out using Legal's test. Fruit juices were treated with sodium nitropruside in pyridine and $\mathrm{NaOH}$. Formation of pink to blood red colour indicates the presence of cardiac glycosides.

Detection of alkaloids: Carried out using Wagner's test. Fruit juice filtrates were treated with Wagner's reagent (Iodine in potassium iodide). Formation of brown/reddish precipitate indicates the presence of alkaloids.

Detection of saponins: Carried out using foam test. 5 $\mathrm{ml}$ of fruit juice was shaken with $2 \mathrm{ml}$ of water. If foam produced persists for ten minutes indicates the presence of saponins.

\section{Probiotication of various fruit juices}

Probiotication experiments were conducted in $150 \mathrm{ml}$ conical flasks each containing $100 \mathrm{ml}$ of various pasteurized fruit juices which were inoculated with a 24 h old culture of L. casei 1423 grown in MRS broth $\left(>10^{5} \mathrm{CFU} / \mathrm{ml}\right)$. The flasks were incubated at $37^{\circ} \mathrm{C}$ for $72 \mathrm{~h}$. 
BV Kumar et al. (2013). Int J Appl Sci Biotechnol, Vol. 1(3): 127-131

\section{Determination of pH, total acidity, sugars and total soluble solids}

Periodical sample collection was done during probiotication were analyzed. The $\mathrm{pH}$ of the juice samples was measured with a hand digital $\mathrm{pH}$ meter (Eutech, Japan), precalibrated with buffers of $\mathrm{pH} 4.0$ and 7.0. Total acidity in juices was determined by titrating with $0.1 \mathrm{~N} \mathrm{NaOH}$ previously standardized using standard oxalic acid and the values were expressed as tartaric acid equivalents. Total soluble solids (TSS) were determined using a hand refractometer (Erma, Japan) in terms of ${ }^{\circ} \mathrm{Bx}\left({ }^{\circ} \mathrm{Brix}\right)$ (Varakumar et al., 2011). Reducing sugars were determined using a spectophotometric method, with 3,5 dinitrosalicylic acid (DNS) (Miller, 1959).

\section{Antioxidants by TLC analysis}

The antioxidant content was determined by using the method of Braca et al., (2001). The tropical fruit juices (sapota, mango, white \& black grape and cantaloupe) were applied on a TLC plate as spots $(100 \mu \mathrm{g} / \mathrm{ml})$ using mobile phase with methanol: acetonitrile in 7:1 ratio. It was allowed to develop the chromatogram for $30 \mathrm{~min}$. After the completion of the chromatogram, the plate was sprayed with DPPH $(0.2 \%$ w/v). The colour change (yellow spot on purple background on TLC plate) is an indication of the presence of antioxidants.

\section{DPPH (1,1-diphenyl-2-picrylhydrazyl) radical scavenging activity}

The DPPH assay was done according to the method described by Varakumar et al. (2011) with some modifications. The stock solution was prepared by dissolving $24 \mathrm{mg}$ DPPH with $100 \mathrm{ml}$ methanol and then stored at $-20^{\circ} \mathrm{C}$. The working solution was obtained by mixing $10 \mathrm{ml}$ stock solution with $45 \mathrm{ml}$ methanol to obtain an absorbance of $1.1 \pm 0.02$ units at $517 \mathrm{~nm}$ using the spectrophotometer. Different volumes of various fruit juices (50-200 $\mu \mathrm{l})$ were allowed to react with DPPH solution (final volume 4 $\mathrm{ml}$ ) and were shaken vigorously then allowed to stand for $30 \mathrm{~min}$ in dark at RT. Methanol is used as a blank in a UV-Vis spectrophotometer. A control sample with no added fruit juice was also analyzed and radicalscavenging activity (\% inhibition) was calculated using the following equation:

$\mathrm{DPPH}$ free radical scavenging activity $(\%)=[(\mathrm{A}$ control - A sample) / A control] $\times 100$

Where $\mathrm{A}=$ absorbance of O.D value.

\section{Results and discussion}

In our study mango, sapota, grape (black and white) and cantaloupe fruit juices were phyto-chemically analysed. The presence of carbohydrates, flavoniods, tannins and glycosides were noticed. The alkaloids and saponins were absent in all the fruit juices tested (Table. 1). We also studied the qualitative analysis of antioxidants using TLC, which has clearly shown that cantaloupe juice has less antioxidant activity than the other fruit juices (Fig. 1).

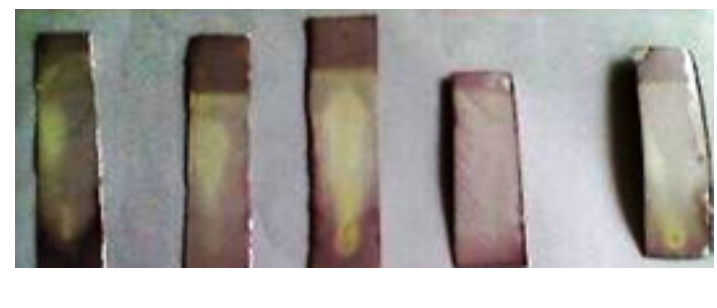
(1)
(2)
(3)
(4)
(5)

Fig. 1: TLC analysis of antioxidants from fruit juices (1=Sapota; $2=$ Mango; 3 =Black grape; 4=Cantaloupe; $5=$ White grape).

In this present study, we observed good survival of probiotic bacteria $L$. casei without adding additional nutrients. Physico-chemical properties of the fresh fruit juices have been studied and the results are presented in Table. 2. Later we have studied the physicochemical properties of probioticated fruit juices at different intervals of fermentation (24, 48 and $72 \mathrm{~h}$ ). The $\mathrm{pH}$ was decreased and acidity was increased in case of all the fruit juices. However, the reducing sugars were decreased due to utilization of the same for the growth of the bacteria (Table 3).

Table 1: Qualitative analysis of various fruit juices for phyto-chemical composition

\begin{tabular}{|l|c|c|c|c|c|}
\hline Components & Mango & Sapota & White grape & Black grape & Cantaloupe \\
\hline Carbohydrates & + & + & + & + & + \\
\hline Flavoniods & + & + & + & + & + \\
\hline Tannis & + & + & + & + & + \\
\hline Glycosides & + & + & - & - & - \\
\hline Alkaloids & - & - & - & - & - \\
\hline Saponins & - & - & + & + & + \\
\hline
\end{tabular}

+: present, -: absent 
BV Kumar et al. (2013). Int J Appl Sci Biotechnol, Vol. 1(3): 127-131

Table 2: Physico-chemical properties of freshly prepared fruit juices

\begin{tabular}{|c|c|c|c|c|c|}
\hline $\begin{array}{c}\text { Name of } \\
\text { the fruit }\end{array}$ & $\begin{array}{c}\text { Juice yield } \\
(\mathbf{m l} / \mathbf{k g})\end{array}$ & $\begin{array}{c}\text { Total soluble solids } \\
(\text { Brix \%) }\end{array}$ & $\begin{array}{c}\text { Titratable } \\
\text { acidity } \mathbf{\%})\end{array}$ & $\mathbf{p H}$ & $\begin{array}{c}\text { Reducing } \\
\text { sugars \% }\end{array}$ \\
\hline Mango & 500 & $20.3 \pm 0.81$ & $0.3 \pm 0.1$ & 4.4 & $18.1 \pm 1.2$ \\
\hline Sapota & 450 & $19.1 \pm 0.76$ & $0.15 \pm 0.01$ & 5.5 & $16.1 \pm 1.0$ \\
\hline Grape (White) & 500 & $15 \pm 1.0$ & $0.14 \pm 0.01$ & 4.6 & $9 \pm 1.0$ \\
\hline Grape (Black) & 550 & $19.3 \pm 0.8$ & $0.17 \pm 0.01$ & 4.5 & $11 \pm 1.0$ \\
\hline Cantaloupe & 400 & $11 \pm 1.0$ & $0.13 \pm 0.01$ & 4.0 & $10.3 \pm 1.5$ \\
\hline
\end{tabular}

Table 3: Physico-chemical analysis of various probioticated fruit juices at different intervals

\begin{tabular}{|l|c|c|c|c|c|}
\hline Name of the fruit juice & Time intervals (h) & TSS Brix \% & Titrable acidity & pH & $\begin{array}{l}\text { Reducing } \\
\text { Sugars }\end{array}$ \\
\hline \multirow{3}{*}{ Mango } & 24 & $20 \pm 1.1$ & $0.70 \pm 0.01$ & 3.8 & $10.7 \pm 0.58$ \\
\cline { 2 - 6 } & 48 & $18 \pm 1.0$ & $0.39 \pm 0.01$ & 3.4 & $5.3 \pm 0.10$ \\
\cline { 2 - 6 } & 72 & $11 \pm 1.0$ & $0.66 \pm 0.07$ & 3.2 & $3.1 \pm 0.11$ \\
\hline Sapota & 24 & $19 \pm 1.3$ & $0.42 \pm 0.06$ & 5.0 & $13.1 \pm 0.60$ \\
\cline { 2 - 6 } & 48 & $16 \pm 1.0$ & $0.46 \pm 0.01$ & 4.5 & $10.3 \pm 0.75$ \\
\cline { 2 - 6 } & 72 & $13 \pm 1.2$ & $0.49 \pm 0.01$ & 4.3 & $5.5 \pm 0.81$ \\
\cline { 2 - 6 } & 24 & $18 \pm 1.3$ & $0.17 \pm 0.06$ & 4.4 & $10.1 \pm 1.0$ \\
\cline { 2 - 6 } & 48 & $16 \pm 1.0$ & $0.22 \pm 0.01$ & 4.2 & $8.3 \pm 0.73$ \\
\hline Cantaloupe & 72 & $14 \pm 1.2$ & $0.28 \pm 0.01$ & 4.0 & $5.5 \pm 0.85$ \\
\cline { 2 - 6 } & 24 & $10 \pm 1.0$ & $0.16 \pm 0.01$ & 4.5 & $5.4 \pm 0.71$ \\
\cline { 2 - 6 } & 48 & $9.3 \pm 1.5$ & $0.17 \pm 0.02$ & 4.3 & $3.6 \pm 0.05$ \\
\hline
\end{tabular}

The antioxidant activity of the fruit juices was quantitatively measured by using DPPH method. In the above method BHT (Butylated hydroxytoluene) used as a standard (Fig. 2). We have estimated the growth of $L$. casei at different time intervals $(24,48$ and $72 \mathrm{~h}$ ) by measuring the OD at $600 \mathrm{~nm}$ and good growth of L. case $i$ was observed in mango, sapota and grape juice when compared with cantaloupe juice (Fig. 3).

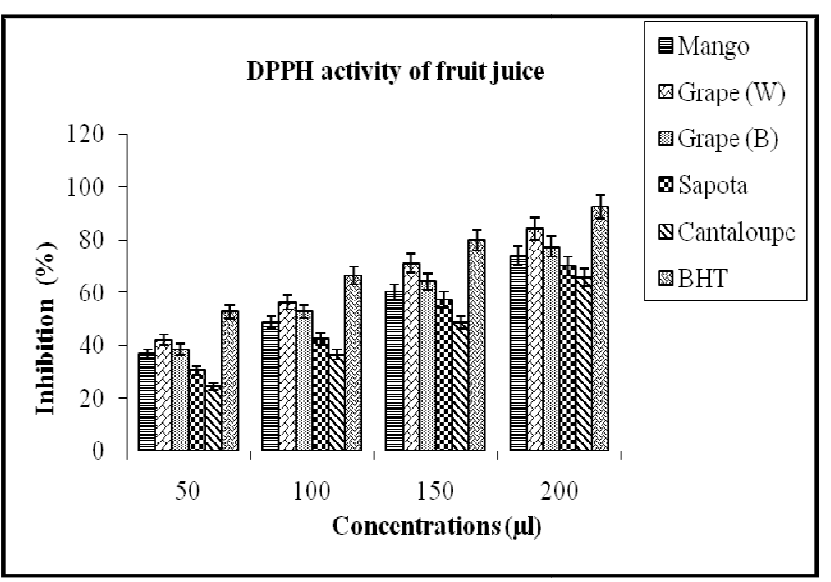

Fig. 2: Measurement of antioxidant activity of probioticated fruit juices using DPPH method

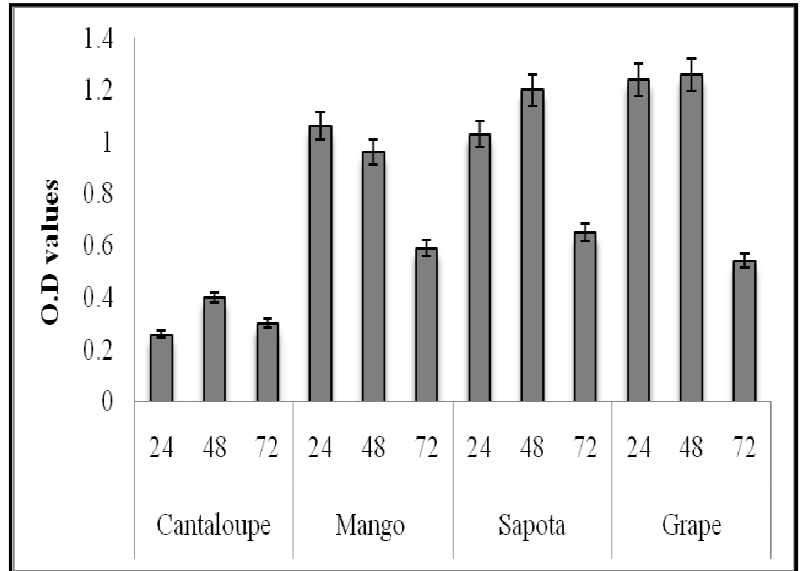

Fig. 3 Estimation of growth in probioticated fruit juices at different time intervals

The preliminary phyto-chemical screening tests may be useful in the detection of the secondary metabolites and subsequently may lead to the drug discovery (Satheesh Kumar et al., 2012) and development. Further, these tests facilitate their quantitative estimation and qualitative separation of pharmacologically active chemical compounds (Varadarajan et al., 2008). The fruit juices generally contain high concentration of 
sugars, acids with good organoleptic properties. These are also a good source of antioxidants, vitamins and minerals. Fruits in the form of fresh fruit juices are included in regular diet. Fruits and fruit juice based drinks are important components of the human diet. People choose fruit juices as a drink for many reasons, including relieving thirst, refreshment and nutrition benefit. Tropical fruit juices could serve as health drinks for consumers with good taste. Fruit juices could serve as a good medium for cultivating probiotics (Mattila-Sandholm et al., 2002). Probiotication of fruit juices is also good for developing health beneficial products particularly to those who are allergic to milk products (Sheehan et al., 2007).

\section{Conclusion}

In our study we have identified that the proven probiotic strain of Lactobacillus casei could survive and capable of rapidly utilizing the nutrients of different fruit juices without adding additional nutrients. Probioticated fruit juices also contained better antioxidants which can provide health benefits to the consumers. Further studies are under progress to characterize the probioticated fruit juices and to test their efficacy for improved immuno-modulation.

\section{Acknowledgement}

We are thankful to Dr.S.C.Basappa, former Deputy Director and Dr.S.V.N.Vijayendra, Scientist, Central Food Technological Research Institute (CFTRI), Mysore, for their encouragement and critical comments on the manuscript.

\section{References}

Betoret N, Puente L, Diaz MJ, Pagan MJ, Garcia MJ, and Gras, ML (2003). Development of probiotic-enriched dried fruits by vacuum impregnation. J. Food Eng. 56: $273-277$.

Braca A, Tommasi ND, Bari LD, Pizza C, Politi M and Morelli I (2001) Natural anti-oxidants from plant material in phenolic compounds in food and their effects on health. J. Nat. Prod. 64: 892-895.

Guarner F, and Schaafsma, GJ (1998). Probiotics. Int. J. of Food Microbiology. 39: 237-238.

Harborne JB (1992) Phyto-chemical methods. Chapman and Hall publications, London. 7-8.

Heenan C, Adams MC, Hosken RW, and Fleet, GH (2004). Survival and sensory acceptability of probiotic microorganisms in a nonfermented frozen vegetarian dessert. Lebensm. Wiss. U. Technol. 37: 461-466.

Kumar YS, Prakasam RS and Reddy OVS (2009). Optimisation of fermentation conditions for mango
(Mangifera indica L.) wine production by employing response surface methodology. Int. J. of Food Sci Technol. 44: 2320-2327.

Luckow T, and Delahunty C (2004). Which juice is 'healthier'? A consumer study of probiotic non-dairy juice drinks, Food Quality and Preference. 15: 751759.

Luckow T, Sheehan V, Fitzgerald G, and Delahunty C (2006). Exposure, health information and flavored masking strategies for improving the sensory quality of probiotic juice. Apetite. 47: 315-325.

Mattila-Sandholm T, Myllärinen, P, Crittenden R, Mogensen, G, Fondén R, and Saarela, M (2002). Technological challenges for future probiotic foods. Int. Dairy Journal. 12: 173-182.

Miller GL (1959) Use of di nitro salicylic acid reagent for determination of reducing sugar, Anal. Chem. 31: 426-428.

Piano MD, Morellic L, Strozzib GP, Allesina S, and Barbab M (2006). Probiotics: from research to consumer. Digestive and Liver Disease. 38: 248-255.

Raganna S (2001). Proximate constituents. In Handbook of Analysis and Quality Control for Fruit and Vegetable Products, 2nd Ed., (S. Ranganna, ed.) pp. 12-17, Tata McGraw-Hill, New Delhi, India.

Reddy LVA, Joshi VK, and Reddy OVS (2012) Utilization of tropical fruits for wine production with special emphasis on mango (Mangifera indica L.) wine. In T. Satyanarayana and Bhavdish Narain Johri (Eds), Microorganisms in Sustainable Agriculture and Biotechnology. Springer, Dordrecht Heidelberg, London New York, 30: 679.

Satheesh Kumar B, Suchetha Kumari N, Vadisha SB, Sharmila K.P, and Prasad BM (2012). Preliminary phytochemical screening of various extracts of Punica granatum pell, whole fruit and seeds. Nitte Uni. J. of Heath Science. 2: 44-48.

Sheehan, VM, Ross P, and Fitzgerald GF (2007). Assessing the acid tolerance and the technological robustness of probiotic cultures for fortification in fruit juices. Innovative Food science and Emerging Technologies 8(2): 279-284.

Siuta-Cruce P and Goulet $\mathrm{J}$ (2001). Improving probiotic survival rates. Food Technology, 55(10): 36-42.

Tuorila, H, and Cardello, AV (2002). Consumer responses to an off/flavor in juice in the presence of specific health claims. Food Qual. Prefer. 13: 561-569.

Varadarajan P, Rathinaswamy G, and Asirvatahm D (2008). Antimicrobial properties and phytochemical constituents of Rheo discolor. Ethnobotanical Leaflet. 12: $841-845$.

Varakumar S, Kumar YS and Reddy, OVS (2011). Carotenoid composition of mango (Mangifera indica L.) wine and its antioxidant activity. J. of Food Biochemistry. 35: 1538-1547. 